\title{
Patterns of portrayal of suicide in print media in an urban setting in western India : a pilot study
}

\author{
Priyanka Jog ${ }^{1}$ \\ Devavrat Harshe ${ }^{2}$ \\ Henal Shah ${ }^{3}$ \\ Ravindra Kamath \\ ${ }^{1}$ Resident Doctor, \\ ${ }^{2}$ Senior Resident Doctor \\ ${ }^{3}$ Professor, \\ ${ }^{4}$ Professor and Head, \\ Department of Psychiatry, BYL Nair Hospital and TN Medical College, Mumbai \\ E-mail-devavrat.harshe@gmail.com
}

\begin{abstract}
Suicide is a major psychosocial issue in all countries. Among many factors affecting the suicide rates, few studies have identified media portrayal to play a significant role in suicidal behavior. The aim of the research was to study the pattern of portrayal of suicide in print media in an urban setting. All news items reporting a suicide or a para-suicide from 26 ${ }^{\text {th }}$ December 2014-25 $5^{\text {th }}$ February 2015 in 5 newspapers with highest circulation figures in Mumbai were included in the study. Guidelines issued by Indian Psychiatric Society on media portrayal of suicide were used to assess the news items on reporting variables. Data was analyzed using descriptive statistics, Chi-square test and Pearson's correlation. The study sample included 150 news items with $80 \%$ reporting suicide. $12 \%$ of the news items were placed on the front page of the newspaper, and in a box. $22 \%$ of the news items were accompanied by a visual aid. $60 \%$ used the word suicide in the headline and $78 \%$ described the method of suicide in a step by step manner. Only 1 news item mentioned suicide helpline and not a single item reported the fact that suicidal behavior can be identified and prevented. Education and awareness programmes for newspaper editors and reporters regarding this sensitive issue are necessary.
\end{abstract}

Key words: suicide, media, suicide prevention.

\section{INTRODUCTION}

Suicide is a major health issue as well as social issue in all countries [1]. A complex and dynamic interaction of genetic, biological, psychosocial and environmental factors culminate in a suicide or a para-suicide [2]. Sadly, India has achieved the unwanted distinction, being the country with the highest number of suicides $\left(1 / 3^{\text {rd }}\right.$ of all suicides in the world) in the world [3]. 
Apart from the factors mentioned above, few factors have been identified as precipitate and influence the suicide rates. Media is one such influence. The impact of print media on suicide rates has been recognized from as early as 1774 , when a spike of copycat suicide ensued after Goethe published "The Sorrows of Young Werther", which even today is known as "The Werther Effect [4]" Werther effect is an increase in suicide rates following media reports of suicide, aka "copycat suicides".

A corollary to this has also been proposed. As the media portrayal can precipitate the suicides, it must also have the potential for playing a protective or preventive role This is proposed as "The Papageno Effect [5]" from the Mozart's opera The Magic Flute, where a suicidal Papageno overcomes his suicidal thoughts by learning new coping strategies.

A lot of research from mental healthcare professionals as well as journalism research groups has supported the effect of media portrayal of suicide on suicide rates. This has resulted in proposition of guidelines by the World Health Organization as well as various governing bodies, media monitoring groups and national governments for media personnel on portrayal of suicide. Recently, Indian Psychiatric Society [2] also published its position statement and guidelines for the media on the topic at hand.

Except New Zealand, where compliance to these guidelines is mandatory by law, and any deviation from is punishable, other countries' guidelines are to be accepted by the media voluntarily. There is no monitoring agency for the same, and studies have reported poor compliance to the guidelines in both print as well as the television media.

We couldn't find an Indian study in literature and felt the need to gauge the level of compliance of our print media houses to the IPS suicide coverage guidelines [2].

The aim of the current research was to study the pattern of portrayal of suicide in print media in an urban setting.

\section{METHODOLOGY}

\section{Inclusion Criteria}

1. All news items covering a suicide/para-suicide from $26^{\text {th }}$ December 2014 to $25^{\text {th }}$ February 2015.

2. All news items/reports covering the issue of suicide from $26^{\text {th }}$ December 2014 to $25^{\text {th }}$ February 2015.

\section{Exclusion Criteria}

1. All news items covering suicide-bomber attacks.

2. All news items using the word "suicide" as a metaphor.

This is a retrospective article review and does not involve human volunteers. We selected 5 newspapers in the Mumbai circle with the highest circulation figures. We used the data from the Registrar of Newspapers in India (RNI) of The Ministry of Information and Broadcasting ${ }^{[1]}$ for selecting the newspapers. This data contains detail on every newspaper registered in India.

We selected the newspapers which were 1) Printed in English or hindi or Marathi and 2) having a Mumbai edition. The newspapers thus selected (with figures of circulation) were 1) The Times of India - Mumbai edition $(10,26,153), 2)$ Daily News and Analysis (DNA) Mumbai edition $(5,76,507)$, 3) Hindustan Times - Mumbai edition $(3,91,568), 4)$ Maharashtra Times - Mumbai edition $(3,02,330)$ and 5) Loksatta - Mumbai edition 
$(2,27,108)$. Newspapers from $26^{\text {th }}$ December 2014 till $26^{\text {th }}$ February 2015 were included in the study.

Each of the newspaper thus selected was then screened and searched entirely by the investigators ( $\mathrm{DH}$ and $\mathrm{PJ}$ ). The newspapers were accessed as hard copies or online epaper editions. News items in every newspaper were selected, which covered a suicide or parasuicide, which included expert comments or editorials or featured columns on suicide for analysis.

The news items were analyzed for the data regarding socio-demographic details of the victim/survivor. Then, the news items were analyzed for quality indicators. We used the recommendations by Indian Psychiatric Society [2], the World Health Organization [6], The Royal Australian and New Zealand College of Psychiatrists [7], Canadian Mental Health Association [8], The Irish Association of Suicidology [9], The Hong Kong Jockey Club Centre for Suicide Research [10] and the recommendations by a joint venture dealing with mental health and suicide in the United States [11].

The recommendations by each of the above mentioned projects were analyzed. We selected guidelines which 1) were common in all recommendations, 2) were objective (had no room for subjective opinion or bias). Few of the guidelines in the recommendations are subjective and can lead to rater bias or even selection bias. For example; most of the guidelines including those by the Indian Psychiatric Society recommend that suicide news item should be matter-of-fact, should not use language which will portray the event as sensational, emotional or glorify/romanticize the event. We used those guidelines, which are objective and have a measurable outcome.

The guidelines thus selected are,

1) Page number

2) Presence of a box around the news,

3) Word count,

4) Photographs of the deceased/location/scene/grieving relatives,

5) Mention of suicide note,

6) Quotes from suicide note,

7) Mentions the word "Suicide" or "Commited suicide" or "Successful/Unsuccessful" terms in headline,

8) Method of suicide mentioned in headline,

9) Method of suicide described in details/step by step manner,

10) Mention of the grief/shock of survivors,

11) Attempt to create public awareness,

12) Mention of suicide helplines/services/treatment options,

13)Stories of those overcoming depression/suicidal thoughts,

14) Mention of mental illness,

15) Warning signs/symptoms mentioned,

16) Treatment options for depression/stress,

17) Possibility of vulnerabilities/triggers,

18) Interview of the police/first responders,

19) Interview/quotes from family,

20) Repetitions/mention of old/other suicides,

21) Cause of suicide blamed on someone

The news items were analyzed and each variable was scored as a dichotomous variable with yes/no response. Quantitative variables such as page number and word count were measured and values were entered. 


\section{Statistical Analysis}

Data was pooled in Microsoft Excel and analyzed in statistical software. Demographic data was analyzed with descriptive statistics. Compliance with media guidelines was assessed with cross-tabs and Chi Square test. Correlations were studied with Pearson's correlation. Statistical significance was at $p<0.05$

\section{RESULTS}

\section{Socio-demographic profile of victims}

A total of 150 news items were selected for the study and analyzed. The distribution of victims was found to be $55 \%$ males $(81 / 150)$ and $45 \%$ females $(69 / 150)$. Mean age of all the victims was $27.02 \pm 13.53$ years, and there was no significant difference between male and female victims in terms of age (28.08 \pm 15.26 [Males] versus $25.72 \pm 9.44$ [Females] years, $\mathrm{t}=1.645, P=0.105$ ). When occupation [Table 1] of the victims of studied, $26 \%$ of the victims were students and $18 \%$ were housewives. The occupation was not mentioned in $21 \%$ cases. $12 \%$ of the victims were unemployed.

\section{Data on suicide attempt}

Majority of the news stories $(120 / 150-80 \%)$ covered a suicide, whereas rest covered a para-suicide $(30 / 150-20 \%) .78 \%$ of the news stories reported attempts involving a single victim, and in $20 \%$ cases, attempt by a couple or a family was reported. Suicide pact was mentioned in 1 suicide attempt. $4 \%$ of suicide attempts were associated with murder or attempt to murder a colleague/spouse or a family.

Coming to the method of suicide, there was no significant impact of gender on the method [Table -2] of suicide ( $X 2=11.286, p=0.186)$. Hanging was the most frequently used method for committing suicide. There was no significant difference in age $(F=0.575, p=0.795)$ on the method of suicide in the study sample.

Table 1 - Occupation of the cases

\begin{tabular}{|c|c|c|c|c|}
\hline & Male & Female & Total & Significance \\
\hline Students & 23 & 16 & 39 & \multirow{9}{*}{$\begin{array}{c}x^{2}=31.862 \\
p<0.001\end{array}$} \\
\hline Housewives & 0 & 27 & 27 & \\
\hline Unemployed & 8 & 1 & 9 & \\
\hline Laborer & 10 & 4 & 14 & \\
\hline Police/Army & 3 & 4 & 7 & \\
\hline Farmers & 6 & 0 & 6 & \\
\hline Clerical & 2 & 4 & 6 & \\
\hline Lawyer & 1 & 0 & 1 & \\
\hline Doctors & 0 & 1 & 1 & \\
\hline
\end{tabular}

\section{Data on placement and presentation of the news item}

We found that $58 \%$ of the news articles were placed [Figure 1] in the $1^{\text {st }} 5$ pages of the newspaper, $12 \%$ of which were on the front page. Placement of the news 
items did not differ across gender $\left(x^{2}=13.161, p=0.357\right)$ and occupation $\left(x^{2}=\right.$ $116.679, p=0.569) .12 \%$ of the news items were placed inside a box. News items with and without the box did not differ significantly in terms of gender $\left(x^{2}=0.881, p=\right.$ $0.282)$ and occupation $\left(x^{2}=3.602, p=0.963\right)$.

Mean word count of news items was $151.92 \pm 97.27$ words. Word count did not differ significantly across gender of the victim ( $t=0.643, p=0.547)$, number of victims $(F=0.087, p=0.917)$, across method of suicide $(F=1.033, p=$ $0.421)$ or page number $(F=1.313, p=0.234) .22 \%$ of the news items were accompanied with a visual aid. $11 \%$ were accompanied by a graphic depicting suicide/location of the attempt, $8 \%$ were accompanied with the photograph of the location of suicide and only 5 news items (3\%) was accompanied with the photograph of the victim. No impact of gender, or occupation or page number was found on use of thevisual aids of victim and location. However, the graphic accompanying the news was significantly more frequent with the news covering para-suicide compared to suicide (14 vs. $7.5 \%, \mathrm{X} 2=9.266, p=0.026)$.

Table 2 - Method of suicide used

\begin{tabular}{|cc|}
\hline $\begin{array}{c}\text { Method of suicide } \\
\text { Consuming poison/overdose } \\
\text { medications }\end{array}$ & Frequency \\
\hline Hanging & 23 \\
\hline Drowning & 36 \\
\hline Jump & 25 \\
\hline Burning self & 26 \\
\hline Stabbing self & 8 \\
\hline Getting run over by train & 2 \\
\hline Self-strangulation & 2 \\
\hline Not mentioned & 2 \\
\hline
\end{tabular}

News Items $(n=150)$

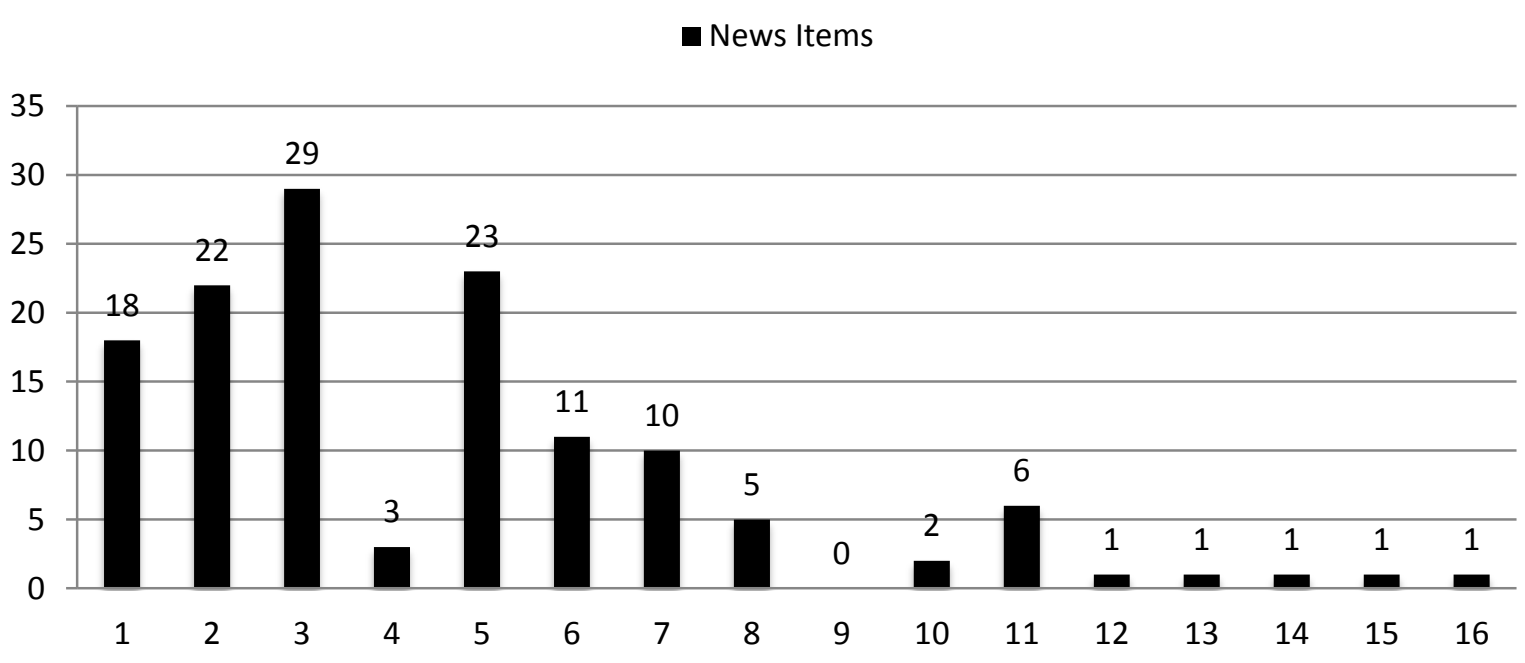

Figure 1 - Placement of news items in the newspaper 


\section{Data on details provided in the news items}

\section{Headlines}

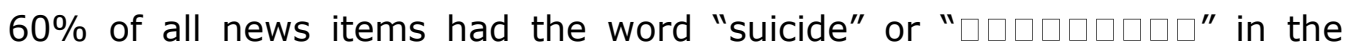
headline. $36 \%$ of the news items mentioned the method of suicide in the headline. $16 \%$ news items mentioned the method of suicide/para-suicide as well as the word "Suicide"

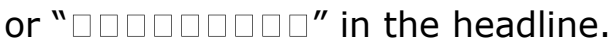

The frequency of the word suicide mentioned in the headline was highest with consumption of poison/overdose of medications (90\%), and was lower for hanging $(50 \%)$, drowning (59\%), jumping from height (55\%), self-emolation (66\%). It was observed that the method of suicide was more frequently mentioned in case of suicide as compared to para-suicide ( 50 vs. $19 \%, \mathrm{X} 2=8.698, p=0.034$ ). Interestingly, the method of suicide was mentioned in headline most frequently $(X 2=40.085, p<0.001)$ in cases of stabbing self to death and being run over by train $(100 \%)$, drowning $(84 \%)$ and jumping from height $(90 \%)$, followed by hanging $(29 \%)$, consuming poison/overdose of medications (5\%). Method was also mentioned most frequently (X2 $=19.933, p=0.030)$ in suicides by labourers $(75 \%)$, followed by farmers $(50 \%)$, housewives $(46 \%)$, students $(26 \%)$ and unemployed $(22 \%)$.

\section{Content}

$65 \%$ of the news items indicated/placed blame on someone the victim knew, or the conditions/environment around the victim. The mention of blame was more frequently in cases of para-suicide compared to suicide ( 86 vs. $63 \%, \mathrm{X} 2=$ $10.785, p=0.013) .7 \%$ of the news items mentioned the suicide note in the content, and $3 \%$ quoted matter from the suicide note. Also, in no news item, the entire suicide suicide note was printed. $78 \%$ of the news items gave a step-by-step account and details of the method employed by the victim in his/her suicide attempt. They also described the suicide location, the time of the day in detail. $20 \%$ of the news items contained a reference to a prior suicide at the same location or by similar method, whereas $6 \%$ news items mentioned the prior attempts by victims. This was significantly more frequent in cases where the suicide attempt was by drowning (59\%).

$30 \%$ of the news items mentioned that the victim was suffering/probably suffering from mental illness as quoted by police/family/neigbours. Most common mental illnesses reported were depression $(16 \%)$, followed by stress $(8 \%)$ and substance use disorders (5\%). 56\% of the news items quoted investigating police officers or the first responders to the victim. However, this was only for news printed on the pages other than the front page. $21 \%$ of the news items interviewed and quoted reactions and comments from the bereavers, however only $8 \%$ mentioned the grief and shock experienced by the relatives. $5 \%$ of the news items used the word successful/unsuccessful or foiled to describe the outcome of the suicide attempt.

\section{De-stigmatization and public awareness}

$8 \%$ of the news stories mentioned and occasionally described certain warning signs and symptoms in victims prior to current suicide attempt. The symptoms described included "being upset", "depressed", "crying spells", and "suicide attempts" in the past few days. $8 \%$ of the news items quoted the bereavers and expressed their shock and grief to the news. Only 1 news item mentioned the (1.3\%) mentioned suicide 
helpline numbers in its content. Not a single news item reported that suicidal behavior can be identified and suicide can be prevented. As mentioned in above section, although $22 \%$ victims were reported to be suffering from mental illness, only 4 news items $(2.6 \%)$ reported the victim being taking treatment for his mental illness. Interestingly, not a single news item mentioned the association between suicide and psychiatric illness and the fact that psychiatric illnesses can be treated. Although as much as $20 \%$ of the news items mentioned or referred to a prior suicide attempt at the same location or by similar method, none mentioned the stories or examples of people who overcame suicidal thoughts/psychiatric illness.

\section{Figure 2 - Various reporting indicators of suicide}

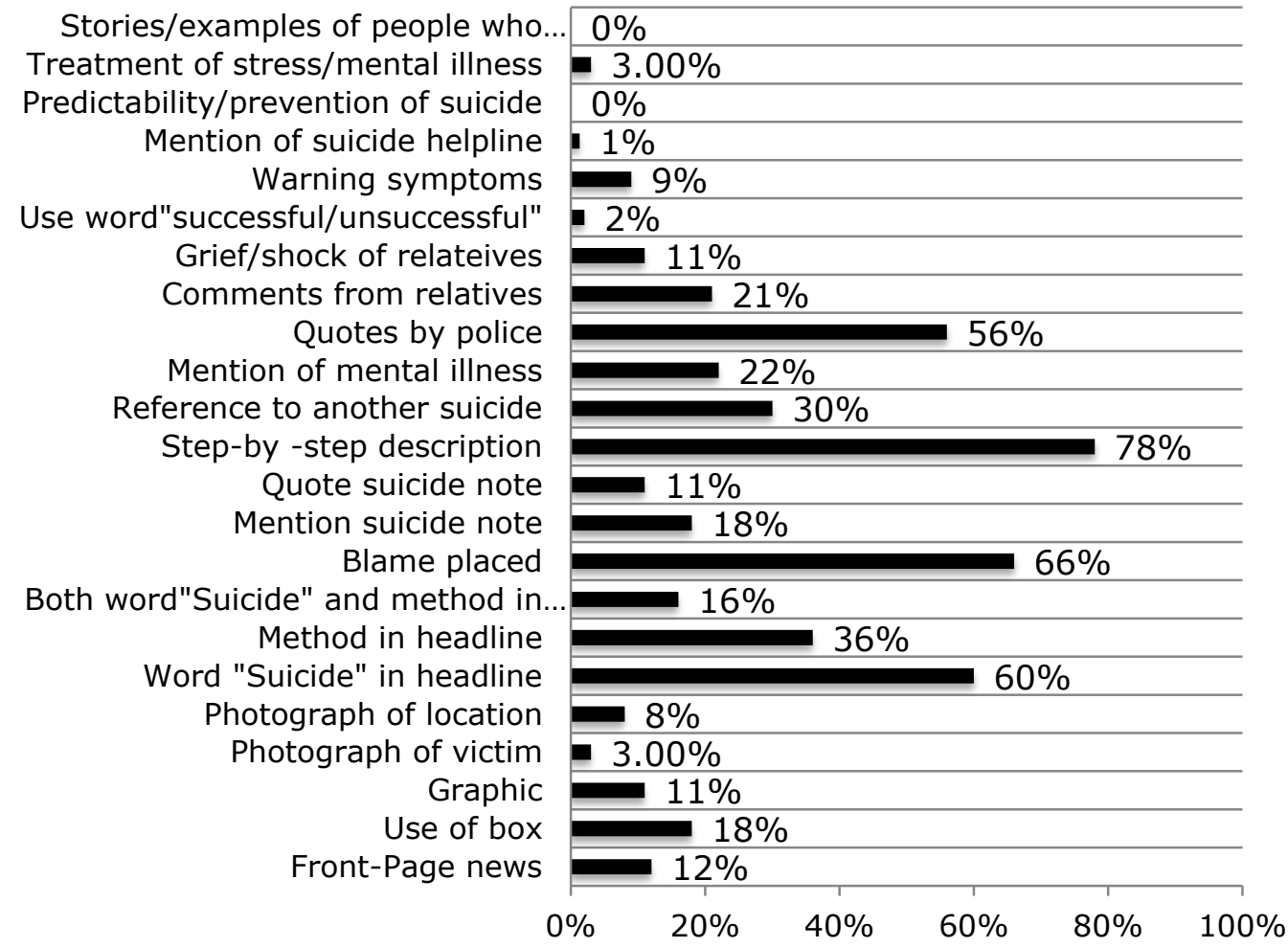

\section{DISCUSSION}

After the guidelines were framed, many studies have been done in western countries to check compliance and adherence of media to the respective guidelines [10-17]. However, since the Indian guidelines were formulated, we could not find an Indian study on this topic.

The first issue to be addressed is the "Werther Effect" itself. The impact and influence of media coverage on suicide rates and copycat suicide has been both supported as well as criticized. Studies have demonstrated an increase in suicide rate after the media coverage of celebrity suicide significantly [12]. A study has also demonstrated that media portrayal of suicide can play a role in preventing suicides as well [13]. This impact of media on an increase in the suicide rates can be explained by the social learning theory [19-20]. The magnitude of copycat suicide behavior will increase, when the vulnerable groups will identify with the victim who commited suicide or the psychosocial fabric around the victim. 
The first aspect of a news article we focused on was, the details regarding the suicide/para-suicide itself. More than $2 / 3^{\text {rd }}$ of all news items in our study had covered a completed suicide with the rest reporting a para-suicide [13]. However, it was seen in the McKenna study that apart from reporting completed suicide and attempted suicide, newspapers in New Zealand also report articles covering suicidal ideations without the suicide attempt. Our study did not find any news article portraying suicidal ideations in the absence of an attempt! This factoid is vital since publishing articles covering suicidal ideations only in the absence of an actual attempt has been linked with reduction in suicide rates [11]. This is hypothesized to be due to i) identification with the victim, ii) stress being placed on the fact that despite the suicidal ideations, the person is going to live.

Both male and female genders were mentioned in equal preference in news articles ( $52 \%$ males, $48 \%$ females). It was also found that, $66 \%$ of the news articles covered the suicide attempts by people in the age group of 20-40 years, which was followed by suicide attempts by adolescents (19\%). In our study, $8 \%$ of the news was on the front page and almost half the news articles were in first 5 pages of the newspaper. Prior studies have also found placement of news on the front page to be $6 \%$ ${ }^{[14]}$ and $4 \%$ [15]. It has been argued that placement of a news covering suicide on the front page gives it an undue prominence. Phillips [16] demonstrated that, placement of news covering suicide on the front-page leads to an increase in the number of suicides within 3 to 30 days of publication. Wasserman and Stack [17-18] also reported an increase in suicide rate over a longer time period.Thus, the guidelines mention that the news covering suicide should be on inside pages, and lower section of the page [3].

Not just the placement of the story, but also the details provided in the headline as well as the news itself can help-both sensationalize the incident, glorify the incident, attribute martyrdom to the victim and sometime romanticize the act of suicide. These details include the suicide note, quotes from the note and mention of the word "suicide" or "commit suicide" in the headline. In our study, nearly $2 / 3^{\text {rd }}$ of the news stories carried the word "Suicide" in the headline, and $43 \%$ mentioned the method of suicide in the headline. These details provide an emotional tone to the news story and help the audience connecting with the victim at an affective level.

If sensationalizing suicide is a problem, normalizing suicide is an even bigger problem. Media is said to normalize the suicide, when they report suicide excessively and report suicide as the coping mechanism or the obvious way out of the problem [13]. For example, "Mr Y commits suicide after break-up". A headline like this portrays that suicide is the obvious step after the break-up. Nearly $60 \%$ of the news stories in our study had placed a blame/attributed someone/environment for the suicide whereas none mentioned the stress-vulnerability model of mental illness and suicide.

Apart from sensationalism and normalization, certain details make it easier for the vulnerable groups to identify with the victim. These include photographs of the victim, location, a graphic demonstrating the attempt and step-by- step description of the method and/or chain of events. In our study, $82 \%$ of the news stories provided a detailed description of the method, $20 \%$ supplemented the news with a visual aid. Scientific research has shown imitation behavior with method in fictional and nonfictional literature [21-23].

Just as mentioning some details are associated with a rise in suicide rates, reporting certain factors has been shown to reduce suicide rates and can have a role in preventive models of suicide [24] for example as discussed above, printing news articles covering only suicidal ideations without the attempt. These details include availability of resources; help seeking behavior, suicide helplines, mention of stress and depression 
associated with suicide and a stress-vulnerability model of suicide. A recent study has demonstrated a reduction in suicide rates after a positive coverage of suicide in television media [25]. Compared to the study in New Zealand (6\%) [13] and the United States $(6 \%)$ [14], only $1(0.6 \%)$ news stories in our study mentioned the suicide helplines and numbers, when nearly $30 \%$ had mentioned that the victim had some mental health related issue for example stress, depression and mental unstability. Mention of suicide helplines, depression and help seeking behavior leads to public awareness regarding contributing factors in suicide and the feeling that, help is available and a solution can be found no matter how hard the problem is.

Not just victim, but the reactions from the society and the survivors also play a role in the media impact on suicide. In almost $60 \%$ stories, quotes from police and survivors were mentioned regarding the investigation, however only 2 stories reported the grief and shock experienced by the survivors after the impact. Portraying shock and grief of survivors is theoretically said to create awareness and a feeling of hope that, despite one's suicidal thoughts, there are loving friends and family members who care for the person and will be tormented after his/her loss.

To conclude, print media comply with suicide coverage guidelines in India as they do in other countries such as the United States and New Zealand. News stories were prominently placed and contained material and details-which sensationalized the news or normalized the event. The factors known to cause a rise in suicide rates were comparable in Indian media as compared to the countries mentioned above. However the more troubling issue is, the preventive aspects of suicide, medical and stressvulnerability models of suicide, help sources available for suicide and the shock-grief experienced by suicide were hardly mentioned. Further research is henceforth required to find Werther Effect and Papageno effect in Indian scenario.

The limitations of our study included a small sample size and selective selection of newspapers from an urban setting. The future directions include a study with a longer time span and a study of suicide portrayal patterns before and after a celebrity suicide.

\section{REFERENCES}

1. The Registrar of Newspapers for India. Press in India 2013-14. 58 ${ }^{\text {th }}$ Annual Report. Ministry of Information and Broadcasting; Government of India ; 2013.

2. Ramadas S, Kuttichira P, John CJ, Isaac M, Kallivayalil RA, Sharma I et al. Position statement and guideline on media coverage of suicide. Indian J Psychiatry 2014;56:10710.

3. Vijayakumar L. Indian research on suicide. Indian J Psychiatry 2010;52(Suppl 1):S291-6.

4. Niederkrotenthaler T, Voracek M, Herberth A, Till B, Strauss M, Etzersdorfer E. Role of media reports in completed and prevented suicide: Werther v. Papageno effects. BJP 2010;197:234-43.

5. Kim JH,Park EC, Nam JM, Park S, Cho J and Kim SJ. The Werther effect of two celebrity suicides: an entertainer and a politician. PLOS ONE 2013;8(2):1-8.

6. Preventing suicide. A resource for media professionals. Department of Mental Health and Substance Abuse. World Health Organization. Geneva 2008.

7. Suicide and the media: The reporting and portrayal of suicide in the media: A resource. The New Zealand Youth Suicide Prevention strategy. The Ministry of Health. Wellington, New Zealand. 1999.

8. Kirchner C (Author) \& Wyatt C (Ed). Reporting suicide: Media guidelines for safe and sensitive coverage. Canadian Mental Health Association - Calgary Region. 2008. 
9. Media guidelines for reporting suicide and self-harm. The Irish Association of Suicidology \& Samaritans ; 2009.

10. Suicide and the media: Recommendations on suicide reporting for media professionals. The Hong Kong Jockey Club. Centre for Suicide Research and Prevention. The University of Hong Kong ; 2010.

11. Reporting on suicide: Recommendations for the media. Centres for disease control, National Institute of Mental Health, Office of the Surgeon General, Substnace Abuse and Mental Health Services Administration, American Foundation for Suicide Prevention, American Association of Suicidology, Anneberg Public Policy Centre ; 2012.

12. The Times of India. India is world's suicide capital with 2.6 lakh cases/year. Published $5^{\text {th }}$ September, 2014. Available on http://timesofindia.indiatimes.com/india/India-is-worldssuicide-capital-with-2-6-lakh-cases/year/articleshow/41737654.cms.

13. Sisask M, Värnik A. Media roles in suicide prevenetion: A systematic review. Int J Environ Res Public Health 2012;9:123-38.

14. Brian McKenna, Katey Thom, Gareth Edwards, Ray Nairn, Anthony O'Brien \& Ingrid Leary. 2010. Reporting of New Zealand Media - Content and case study analysis. Centre for Mental Health Research, The University of Auckland, Auckland: Te Pou ; 2010.

15. Tatum PT, Canetto SS, Slater MD. Suicide coverage in US newspapers following the publication of the media guidelines. Suicide Life Threat Behav 2010;40(5):524-534.

16. Machlin A, Skehan J, Sweet M, Wake A, Fletcher J, Spittal M et al. Reporting suicide: interpreting media guidelines. Australian Journalism Review 2005;34(2):45-56.

17. Phillips DP. Airplane accidents, murder, and the mass media: Towards a speitheory of imitation and suggestion. Social Forces 1980;58:1001-24 [ic:

18. Wasserman IM. Imitation and suicide: A re-examination of the Werther effect. American Sociological Review 1984;49(3):427-36.

19. Stack S. A reanalysis of the impact of non-celebrity suicides: A research note. Social Psychiatry and Psychiatric Epidemiology 1990;25(5):269-73.

20. Bandura A. Social cognitive theory of mass communication. Media Psychology 2001;3(3):265-99.

21. Blood R\& Pirkis J. Suicide and the media: Part III. Theoretical issues. Crisis 2001;22(4): 163-69.

22. Etzersdorfer E, Voracek M, Sonneck G. A dose-response relationship between imitational suicides and newspaper distribution. Archives of Suicide Research 2004;8:137-45.

23. Hawton K, Simkin S, Deeks JJ, O'Connor S, Keen A, Altman DG, et al. Effects of a drug overdose in a television drama on presentations to hospital for self poisoning: Time series and questionnaire study. British Medical Journal 1999;318:972-7.

24. Kiu KY, Beautrais A, Caine E, Chan K, Chao A, Conwell Y, et al. Charcoal burning suicides in Hong Kong and urban Taiwan: An illustration of the impact of a novel suicide method on overall regional rates. Journal of Epidemiology and Community Health 2007;61(3):248-53.

25. Romer D, Jamieson PE, Jamieson $\mathrm{KH}$. Are news reports of suicide contagious? A stringent test in six U.S. cities. Journal of Communication 2006;56(2):253-270.

Acknowledgements - Nil

Conflict of Interest - Nil

Funding - Nil. 